Biophysical skin measurements to evaluate the effectiveness of photobiomodulation therapy in the prevention of acute radiation dermatitis in breast cancer patients

Peer-reviewed author version

ROBIJNS, Jolien; Censabella, S.; Claes, S.; Pannekoeke, L.; Bussé, L.; Colson, D.; Kaminski, I.; LODEWIJCKX, Joy; BULENS, Paul; MAES, Annelies; Noé, L.; Brosens, M.; Timmermans, A.; LAMBRICHTS, Ivo; SOMERS, Veerle \& MEBIS, Jeroen (2018) Biophysical skin measurements to evaluate the effectiveness of photobiomodulation therapy in the prevention of acute radiation dermatitis in breast cancer patients. In: Supportive care in cancer, 27(4), p. 1245-1254.

DOI: $10.1007 / \mathrm{s} 00520-018-4487-4$

Handle: http://hdl.handle.net/1942/28110 


\section{Dear Author}

Here are the proofs of your article.

- You can submit your corrections online, via e-mail or by fax.

- For online submission please insert your corrections in the online correction form. Always indicate the line number to which the correction refers.

- You can also insert your corrections in the proof PDF and email the annotated PDF.

- For fax submission, please ensure that your corrections are clearly legible. Use a fine black pen and write the correction in the margin, not too close to the edge of the page.

- Remember to note the journal title, article number, and your name when sending your response via e-mail or fax.

- Check the metadata sheet to make sure that the header information, especially author names and the corresponding affiliations are correctly shown.

- Check the questions that may have arisen during copy editing and insert your answers/corrections.

- Check that the text is complete and that all figures, tables and their legends are included. Also check the accuracy of special characters, equations, and electronic supplementary material if applicable. If necessary refer to the Edited manuscript.

- The publication of inaccurate data such as dosages and units can have serious consequences. Please take particular care that all such details are correct.

- Please do not make changes that involve only matters of style. We have generally introduced forms that follow the journal's style.

- Substantial changes in content, e.g., new results, corrected values, title and authorship are not allowed without the approval of the responsible editor. In such a case, please contact the Editorial Office and return his/her consent together with the proof.

- If we do not receive your corrections within 48 hours, we will send you a reminder.

- Your article will be published Online First approximately one week after receipt of your corrected proofs. This is the official first publication citable with the DOI. Further changes are, therefore, not possible.

- The printed version will follow in a forthcoming issue.

\section{Please note}

After online publication, subscribers (personal/institutional) to this journal will have access to the complete article via the DOI using the URL:

http://dx.doi.org/10.1007/s00520-018-4487-4

If you would like to know when your article has been published online, take advantage of our free alert service. For registration and further information, go to:

http://www.link.springer.com.

Due to the electronic nature of the procedure, the manuscript and the original figures will only be returned to you on special request. When you return your corrections, please inform us, if you would like to have these documents returned. 


\section{Metadata of the article that will be visualized in OnlineFirst}

1 Article Title Biophysical skin measurements to evaluate the effectiveness of photobiomodulation therapy in the prevention of acute radiation dermatitis in breast cancer patients

\begin{tabular}{|c|c|c|c|}
\hline 2 & \multicolumn{3}{|l|}{ Article Sub- Title } \\
\hline 3 & $\begin{array}{l}\text { Article Copyright - } \\
\text { Year }\end{array}$ & \multicolumn{2}{|c|}{$\begin{array}{l}\text { Springer-Verlag GmbH Germany, part of Springer Nature } 2018 \\
\text { (This will be the copyright line in the final PDF) }\end{array}$} \\
\hline 4 & Journal Name & \multicolumn{2}{|c|}{ Supportive Care in Cancer } \\
\hline 5 & \multirow{8}{*}{$\begin{array}{l}\text { Corresponding } \\
\text { Author }\end{array}$} & Family Name & Robijns \\
\hline 6 & & Particle & \\
\hline 7 & & Given Name & Jolien \\
\hline 8 & & Suffix & \\
\hline 9 & & Organization & Hasselt University \\
\hline 10 & & Division & Faculty of Medicine \& Life Sciences \\
\hline 11 & & Address & Martelarenlaan 42, Hasselt 3500, Belgium \\
\hline 12 & & e-mail & jolien.robijns@uhasselt.be \\
\hline 13 & \multirow{8}{*}{ Author } & Family Name & Censabella \\
\hline 14 & & Particle & \\
\hline 15 & & Given Name & Sandrine \\
\hline 16 & & Suffix & \\
\hline 17 & & Organization & Jessa Hospital \\
\hline 18 & & Division & Department of Medical Oncology \\
\hline 19 & & Address & Stadsomvaart 11, Hasselt, Belgium \\
\hline 20 & & e-mail & \\
\hline 21 & \multirow{8}{*}{ Author } & Family Name & Claes \\
\hline 22 & & Particle & \\
\hline 23 & & Given Name & Stefan \\
\hline 24 & & Suffix & \\
\hline 25 & & Organization & Jessa Hospital \\
\hline 26 & & Division & Limburg Oncology Centre \\
\hline 27 & & Address & Stadsomvaart 11, Hasselt, Belgium \\
\hline 28 & & e-mail & \\
\hline 29 & \multirow{2}{*}{ Author } & Family Name & Pannekoeke \\
\hline 30 & & Particle & \\
\hline
\end{tabular}




\begin{tabular}{|c|c|c|c|}
\hline 31 & & Given Name & Luc \\
\hline 32 & & Suffix & \\
\hline 33 & & Organization & Jessa Hospital \\
\hline 34 & & Division & Limburg Oncology Centre \\
\hline 35 & & Address & Stadsomvaart 11, Hasselt, Belgium \\
\hline 36 & & e-mail & \\
\hline 37 & & Family Name & Bussé \\
\hline 38 & & Particle & \\
\hline 39 & & Given Name & Lore \\
\hline 40 & A uthor & Suffix & \\
\hline 41 & Autror & Organization & Hasselt University \\
\hline 42 & & Division & Faculty of Medicine \& Life Sciences \\
\hline 43 & & Address & Martelarenlaan 42, Hasselt 3500, Belgium \\
\hline 44 & & e-mail & \\
\hline 45 & & Family Name & Colson \\
\hline 46 & & Particle & \\
\hline 47 & & Given Name & Dora \\
\hline 48 & A & Suffix & \\
\hline 49 & Autror & Organization & Hasselt University \\
\hline 50 & & Division & Faculty of Medicine \& Life Sciences \\
\hline 51 & & Address & Martelarenlaan 42, Hasselt 3500, Belgium \\
\hline 52 & & e-mail & \\
\hline 53 & & Family Name & Kaminski \\
\hline 54 & & Particle & \\
\hline 55 & & Given Name & Iris \\
\hline 56 & A tho & Suffix & \\
\hline 57 & Айाण & Organization & Hasselt University \\
\hline 58 & & Division & Faculty of Medicine \& Life Sciences \\
\hline 59 & & Address & Martelarenlaan 42, Hasselt 3500, Belgium \\
\hline 60 & & e-mail & \\
\hline 61 & & Family Name & Lodewijckx \\
\hline 62 & & Particle & \\
\hline 63 & & Given Name & Joy \\
\hline 64 & A uthor & Suffix & \\
\hline 65 & Autror & Organization & Hasselt University \\
\hline 66 & & Division & Faculty of Medicine \& Life Sciences \\
\hline 67 & & Address & Martelarenlaan 42, Hasselt 3500, Belgium \\
\hline 68 & & e-mail & \\
\hline
\end{tabular}




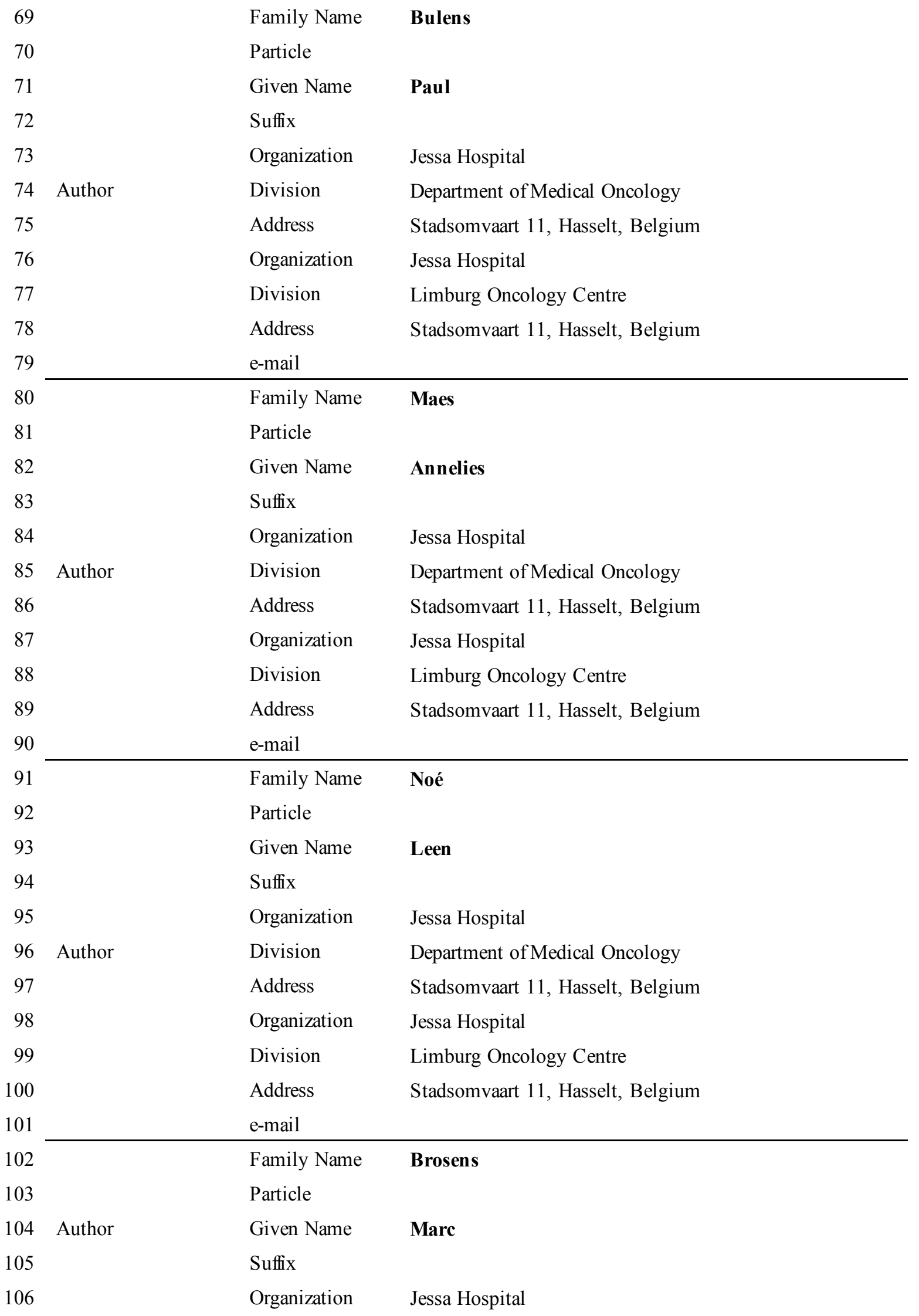




\begin{tabular}{|c|c|c|c|}
\hline 107 & & Division & Department of Medical Oncology \\
\hline 108 & & Address & Stadsomvaart 11, Hasselt, Belgium \\
\hline 109 & & Organization & Jessa Hospital \\
\hline 110 & & Division & Limburg Oncology Centre \\
\hline 111 & & Address & Stadsomvaart 11, Hasselt, Belgium \\
\hline 112 & & e-mail & \\
\hline 113 & \multirow{8}{*}{ Author } & Family Name & Timmermans \\
\hline 114 & & Particle & \\
\hline 115 & & Given Name & An \\
\hline 116 & & Suffix & \\
\hline 117 & & Organization & Jessa Hospital \\
\hline 118 & & Division & Department of Dermatology \\
\hline 119 & & Address & Stadsomvaart 11, Hasselt, Belgium \\
\hline 120 & & e-mail & \\
\hline 121 & \multirow{8}{*}{ Author } & Family Name & Lambrichts \\
\hline 122 & & Particle & \\
\hline 123 & & Given Name & Ivo \\
\hline 124 & & Suffix & \\
\hline 125 & & Organization & Hasselt University \\
\hline 126 & & Division & Faculty of Medicine \& Life Sciences \\
\hline 127 & & Address & Martelarenlaan 42, Hasselt 3500, Belgium \\
\hline 128 & & e-mail & \\
\hline 129 & \multirow{8}{*}{ Author } & Family Name & Somers \\
\hline 130 & & Particle & \\
\hline 131 & & Given Name & Veerle \\
\hline 132 & & Suffix & \\
\hline 133 & & Organization & Hasselt University \\
\hline 134 & & Division & Faculty of Medicine \& Life Sciences \\
\hline 135 & & Address & Martelarenlaan 42, Hasselt 3500, Belgium \\
\hline 136 & & e-mail & \\
\hline 137 & \multirow{8}{*}{ Author } & Family Name & Mebis \\
\hline 138 & & Particle & \\
\hline 139 & & Given Name & Jeroen \\
\hline 140 & & Suffix & \\
\hline 141 & & Organization & Hasselt University \\
\hline 142 & & Division & Faculty of Medicine \& Life Sciences \\
\hline 143 & & Address & Martelarenlaan 42, Hasselt 3500, Belgium \\
\hline 144 & & Organization & Jessa Hospital \\
\hline
\end{tabular}




\begin{tabular}{|c|c|c|c|}
\hline 145 & & Division & Department of Medical Oncology \\
\hline 146 & & Address & Stadsomvaart 11, Hasselt, Belgium \\
\hline 147 & & Organization & Jessa Hospital \\
\hline 148 & & Division & Limburg Oncology Centre \\
\hline 149 & & Address & Stadsomvaart 11, Hasselt, Belgium \\
\hline 150 & & e-mail & \\
\hline 151 & & Received & 30 April 2018 \\
\hline 152 & Schedule & Revised & \\
\hline 153 & & Accepted & 24 September 2018 \\
\hline
\end{tabular}

154 Abstract

Purpose: The purpose of this study was to evaluate objectively the effectiveness of photobiomodulation therapy (PBMT) for the prevention of acute radiation dermatitis (ARD) by using biophysical skin measurements. Methods: A randomized, placebo-controlled trial with 120 breast cancer patients who underwent an identical radiotherapy (RT) regimen post-lumpectomy was performed (TRANSDERMIS trial). Patients were randomized to receive PBM (808 $\mathrm{nm} \mathrm{CW/905} \mathrm{nm} \mathrm{pulsed,} 168 \mathrm{~mW} / \mathrm{cm}^{2}$, spot size $19.6 \mathrm{~cm}^{2}$, fluence $4 \mathrm{~J} / \mathrm{cm}^{2}$ ) or placebo treatments from the first day ofRT $(2 \times /$ week). Biophysical skin measurements were collected to assess the skin pigmentation and barrier function. Measurements were collected at the first day of RT, a RT dose of 40 Gray (Gy), and the end of RT (66 Gy).

Results: The incidence of moist desquamation was significantly higher in the control than in the PBMT group at the end of RT (30 vs. 7\%, respectively, odds ratio $=6, p=0.004$ ). The biophysical skin measures showed that the mean percentage change from the baseline transepidermal water loss (TEWL), erythema, and melanin values was significantly higher in the control than in the PBMT group at the end of RT $(p s<0.05)$. Logistic regression analysis revealed that the risk on moist desquamation was significantly increased for patients with a large $(>800 \mathrm{cc}$ ) breast volume (odds ratio $=4, p=0.017$ ). Conclusions: This is the first randomized controlled trial demonstrating by objective measurements that PBMT is effective in reducing the incidence of moist desquamation in breast cancer patients undergoing RT. Additionally, a large breast volume is an important risk factor for the development of moist desquamation.

155 Keywords separated Breast cancer - Photobiomodulation therapy - Radiotherapy - Skin toxicity by ' - ' Radiation dermatitis - Objective skin evaluation

156 Foot note This research was orally presented at the International Symposium of the information Multinational Association of Supportive Care in Cancer and the International Society for Oral Oncology (MASCC/ISOO; June 28-30, 2018, Vienna, Austria).

The online version of this article (https://doi.org/10.1007/s00520-018-4487-4) contains supplementary material, which is available to authorized users.

\section{Electronic supplementary mate rial}




\section{AUTHOR'S PROOF!}

ESM 1

(DOCX $130 \mathrm{~kb}$ ) 
4

\title{
Biophysical skin measurements to evaluate the effectiveness of photobiomodulation therapy in the prevention of acute radiation dermatitis in breast cancer patients
}

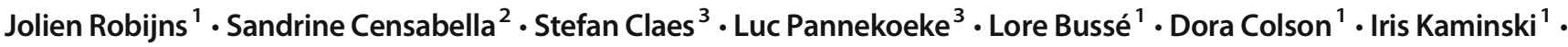 \\ Joy Lodewijckx ${ }^{1}$ • Paul Bulens ${ }^{2,3}$ - Annelies Maes ${ }^{2,3} \cdot$ Leen Noé $^{2,3}$ - Marc Brosens ${ }^{2,3} \cdot$ An Timmermans $^{4}$. \\ Ivo Lambrichts ${ }^{1} \cdot$ Veerle Somers $^{1} \cdot$ Jeroen Mebis ${ }^{1,2,3}$ \\ Received: 30 April 2018 / Accepted: 24 September 2018 \\ (C) Springer-Verlag GmbH Germany, part of Springer Nature 2018
}

\begin{abstract}
Purpose The purpose of this study was to evaluate objectively the effectiveness of photobiomodulation therapy (PBMT) for the prevention of acute radiation dermatitis (ARD) by using biophysical skin measurements.

Methods A randomized, placebo-controlled trial with 120 breast cancer patients who underwent an identical radiotherapy (RT) regimen post-lumpectomy was performed (TRANSDERMIS trial). Patients were randomized to receive PBM ( $808 \mathrm{~nm}$ CW/ $905 \mathrm{~nm}$ pulsed, $168 \mathrm{~mW} / \mathrm{cm}^{2}$, spot size $19.6 \mathrm{~cm}^{2}$, fluence $\left.4 \mathrm{~J} / \mathrm{cm}^{2}\right)$ or placebo treatments from the first day of RT $(2 \times /$ week $)$. Biophysical skin measurements were collected to assess the skin pigmentation and barrier function. Measurements were collected at the first day of RT, a RT dose of 40 Gray (Gy), and the end of RT (66 Gy).

Results The incidence of moist desquamation was significantly higher in the control than in the PBMT group at the end of RT (30 vs. $7 \%$, respectively, odds ratio $=6, p=0.004)$. The biophysical skin measures showed that the mean percentage change from the baseline transepidermal water loss (TEWL), erythema, and melanin values was significantly higher in the control than in the PBMT group at the end of RT $(p s<0.05)$. Logistic regression analysis revealed that the risk on moist desquamation was significantly increased for patients with a large $(>800 \mathrm{cc}$ ) breast volume (odds ratio $=4, p=0.017$ ).

Conclusions This is the first randomized controlled trial demonstrating by objective measurements that PBMT is effective in reducing the incidence of moist desquamation in breast cancer patients undergoing RT. Additionally, a large breast volume is an important risk factor for the development of moist desquamation.
\end{abstract}

Keywords Breast cancer · Photobiomodulation therapy $\cdot$ Radiotherapy $\cdot$ Skin toxicity $\cdot$ Radiation dermatitis $\cdot$ Objective skin evaluation

This research was orally presented at the International Symposium of the Multinational Association of Supportive Care in Cancer and the International Society for Oral Oncology (MASCC/ISOO; June 28-30, 2018, Vienna, Austria).

Electronic supplementary material The online version of this article (https://doi.org/10.1007/s00520-018-4487-4) contains supplementary material, which is available to authorized users.

Jolien Robijns

jolien.robijns@uhasselt.be

1 Faculty of Medicine \& Life Sciences, Hasselt University, Martelarenlaan 42, 3500 Hasselt, Belgium
2 Department of Medical Oncology, Jessa Hospital, Stadsomvaart 11, Hasselt, Belgium

3 Limburg Oncology Centre, Jessa Hospital, Stadsomvaart 11, Hasselt, Belgium

4 Department of Dermatology, Jessa Hospital, Stadsomvaart 11, Hasselt, Belgium 


\section{Introduction}

Acute radiation dermatitis (ARD) is a severe side effect occurring in about $90-95 \%$ of the cancer patients undergoing radiotherapy (RT) [1]. This is a cutaneous reaction that is caused by direct damage of ionizing radiation, which manifests 2-4 weeks after the first RT session [2].

In normal healthy skin, the superficial cells of the epidermis (i.e., upper skin layer) are shed through normal desquamation and replaced by stem cells from the underlying basal layer. From the first RT dose, stem cells within the basal layer of the epidermis are destroyed, leading to a disruption in the self-renewing property of the skin. During RT, this process continues which will negatively affect the skin barrier function and the wound healing process. This ultimately results in changes of the skin structure and vasculature, clinically characterized by erythema, dryness, flaking skin, pruritus, folliculitis (i.e., skin rash), and hyperpigmentation. Due to the compromised skin barrier function and cutaneous immune system, the skin will become more susceptible to water loss, chemical substances, allergens, ultraviolet radiation (UV), and infections [3, 4].

Clinically, ARD is evaluated by the criteria of the Radiation Therapy Oncology Group (RTOG) into three grades: mild erythema and dry desquamation (grade 1), bright erythema and moist desquamation in skin folds (grade 2), and confluent moist desquamation (grade 3). However, this grading system lacks objectivity [5].

A variety of biophysical skin techniques are available to measure the skin pigmentation, hydration, $\mathrm{pH}$, blood flow, and sebum level in order to investigate the underlying physiological mechanism of ARD [6].

Up to now, the evidence for a general consensus on the prevention and management of ARD is limited. Nevertheless, the Multinational Association of Supportive Care in Cancer (MASCC) developed skin care guidelines concerning the prevention and treatment of RD in 2013. Still, many RT centers develop their own skin care protocol [7].

Photobiomodulation therapy (PBMT) is the application of visible and/or (near-) infrared light at a low power on tissue to stimulate the wound healing process and reduce inflammation and pain [8]. There is evidence that PBMT could be used as a new preventive and therapeutic tool in the management of ARD [9-12]. Recently, our research group performed two clinical trials in which we demonstrated that PBMT is able to prevent the development of ARD grade 2 or higher in breast cancer patients by clinically evaluating the skin reactions by the RTOG grading $[13,14]$.

In this project, we evaluated the effectiveness of PBMT in the prevention of ARD in breast patients by objectively assessing the skin hydration, transepidermal water loss (TEWL), and pigmentation.

\section{Material and methods}

\section{Study design and setting}

88

This was a secondary analysis of the TRANSDERMIS trial, a monocentric, prospective, placebo-controlled, randomized controlled trial (RCT) [14], to evaluate objectively the effectiveness of PBMT in breast cancer patients undergoing RT. Female patients with unilateral breast cancer who were treated at the RT Department of the Limburg Oncology Centre (Jessa Hospital, Hasselt, Belgium) were screened on eligibility between April 2015 and June 2017. The study was approved by the ethics committees of the Jessa Hospital and the University of Hasselt (B243201524443) and was conducted according to the Declaration of Helsinki. The study was registered at ClinicalTrials.gov (NCT02443493).

\section{Study population}

To be eligible for the study, patients needed to fulfill the following criteria: female, diagnosed with primary unilateral breast cancer, underwent lumpectomy, scheduled to undergo a RT regimen consisting of 25 fractions of 2 Gray (Gy) to the whole breast and 8 fractions of 2 Gy to the tumor region (total RT dose $66 \mathrm{~Gy}$ ). Patients were excluded when they met the following criteria: irradiation to the same breast in the past, hypofractionated RT, mastectomy, metastatic disease, concomitant chemotherapy, and infection of the to-be-irradiated zone. Eligible patients were recruited during the $\mathrm{CT}$ simulation session, approximately 2 weeks before the start of the RT. Written informed consent of all patients was collected before study participation.

\section{Randomization and blinding}

The planning target volume (PTV) of the eligible patients was used to stratify them into three groups: small $(<450 \mathrm{cc})$, medium $(450-800 \mathrm{cc})$, and large breasts (> $800 \mathrm{cc})$ [15]. Patients were randomly assigned to the control or PBMT group in a 1:1 ratio based on a computer-generated random number list, which was held by a researcher who was not involved in the clinical part of the study. Allocation was concealed to the PBM operator until the first treatment session. Both the participating patient and the outcome assessor were blinded until the last treatment session.
89 90 91 92 93 94 95 96 97 98 99 


\section{Interventions}

\section{Radiotherapy}

The Eclipse ${ }^{\mathrm{TM}}$ treatment planning system was used to plan the RT sessions (version 11.0, Varian Medical System, Palo Alto, CA). The standard RT regimen consisted of 25 daily fractions (2 Gy/fraction, 5 fractions/week) to the whole breast followed by boost of 8 fractions ( $2 \mathrm{~Gy} /$ fraction, 5 fractions/week) to the tumor bed during a period of 6 to 7 weeks (total RT dose of 66 Gy). The whole breast was irradiated with two tangential photon (half) beams set up isocentrically using a 6 -MV or a $6+15$ MV linear accelerator (Clinac ${ }^{\circledR}$ DHX, Varian Medical Systems, Palo Alto, CA) and the tumor region with a two-field conformal photon (4-15 MV) or a one-field vertical electron $(6-15 \mathrm{MeV})$ beam. A selected ${ }^{1}$ group of patients were irradiated using the deep inspiration breath-hold (DIBH) in order to reduce the mean heart dose (MHD).

\section{Topical skin care treatment}

Each patient was individually advised to follow the general skin care guidelines (e.g., wear loose fit clothing, gentle washing with or without mild soap, patting dry with a soft towel instead of rubbing). Further, the patients were instructed to apply a topical, hydroactive colloid gel (Flamigel®, Flen Pharma, Kontich, Belgium) on the irradiated zone $(3 \times /$ day $)$, starting at the first day of RT. Foam, absorbent, self-adhesive silicone dressings (Mepilex ${ }^{\circledR}$, Mölnlycke Health Care, Gothenburg, Sweden) were used in the case of painful skin reactions and/or moist desquamation.

\section{PBMT}

PBMT was applied from the first until the last day of RT ( $2 \times /$ week, 14 sessions) by a trained operator using the class IV MLS® M6 laser (ASA Srl, Vicenza, Italy), as described previously [14]. This device is commercially available, built in compliance with EC/EU rules, received FDA approval, and is CE certified. It consists of two laser diodes with different wavelengths $(808-905 \mathrm{~nm})$, peak powers (1.1-25 W), and emission modes (continuous and pulsed). Both diodes work simultaneously and

\footnotetext{
${ }^{1}$ DIBH was used when the patients matched the following criteria: bilateral breast cancer; left-sided breast cancer and lymph node metastases under the age of 70 years; left-sided breast cancer and lymph node metastases above the age of 70 years and undergoing chemotherapy; left-sided breast cancer without lymph node metastasis but with a MHD $\geq 35 \mathrm{~Gy}$. DIBH was applied using the Varian Real-Time Position Management (RPM) gating system (Varian Medical System, Palo Alto, CA).
}

synchronously with coincident propagation axes (average radiant power $3.3 \mathrm{~W}$ ). The energy density (fluence) was set at $4 \mathrm{~J} / \mathrm{cm}^{2}$ based on earlier recommendations and on our clinical experience $[13,16]$. During the PBMT sessions, the whole irradiated area was treated (whole breast, inframammary fold, and axilla). The complete list of PBMT parameters can be found in Table 1. The PBMT parameters were selected based on the successful results of our previous trial (DERMIS trial) [14] and on the guidelines of Zecha et al. [17].

During the sham treatments of the control group, the PBM device did not emit light but made the same sound as an active device. All patients, independently of their treatment group, wore safety glasses and eye shields to avoid any perceived risk of eye damage and to blind them during the PBM or sham sessions.

\section{Outcome measures}

Patient data

Clinical information regarding the patient's personal and disease- and treatment-related characteristics was collected via patient questionnaires and the patient's medical charts.

\section{RTOG grading}

Clinically, the severity of ARD was evaluated by the criteria of the Radiation Therapy Oncology Group/European Organization for Research and Treatment of Cancer (RTOG/EORTC [5]). Two experienced RT nurses performed this in a blinded manner.

\section{Objective skin measurements}

In order to assess the impact of RT on the skin barrier function, the transepidermal water loss (TEWL) and the skin hydration level were determined. TEWL was measured by the Tewameter ${ }^{\circledR}$ TM300 (Courage-Khazaka, Cologne, Germany), according to the guidelines published both by the standardization group of the European Contact Dermatitis Society [18] and by the European group on Efficacy Measurements of Cosmetics and Other topical products [19]. The skin hydration was measured with the Corneometer ${ }^{\circledR}$ (Courage-Khazaka, Cologne, Germany) according to Heinrich et al. [20]. A reflectance spectrophotometer, Mexameter ${ }^{\circledR}$ MX18 (Courage-Khazaka, Cologne, Germany), was used to measure the pigmentation of the skin (e.g., melanin and erythema) as previously described by Clarys et al. [21].

All four measurements (e.g., TEWL, hydration, erythema, and melanin) were taken at the four quadrants of each breast (irradiated and non-irradiated), with three 


\section{t1.2 PBMT parameters}

$\mathrm{t} 1.3$

t1.10 Irradiation parameters

$\mathrm{t} 1.11$

t1.12

$\mathrm{t} 1.13$

t1.14

$\mathrm{t} 1.15$

t1.16

$\mathrm{t} 1.17$

$\mathrm{t} 1.18$

$\mathrm{t} 1.19$

$\mathrm{t} 1.20$

$\mathrm{t} 1.21$

$\mathrm{t} 1.22$

t1.23 Treatment parameters measurements per quadrant (see Online Resource 1). The average values of these measurements were taken as a value for the whole breast. The measurements were carried out after a 30-min acclimatization period at room temperature $\left(20-22{ }^{\circ} \mathrm{C}\right)$ and $40-60 \%$ humidity. The final objective measurements were described as percentages in 219 order to calculate deviations from pre-treatment baseline 220 values, also termed as indexes. Therefore, the following 221 formula was used:

$\left[\left(\frac{\text { Obj.measure irradiated breast at indicated time/Obj.measure control breast at indicated time }}{\text { Obj.measure irradiated breast at baseline/Obj.measure control breast at baseline }}\right)-1\right] \times 100 \%$

Table 1 Photobiomodulation parameters

\begin{tabular}{lll}
\hline Device information & Manufacturer & ASA Srl \\
& Model identifier & MLS® laser M6 \\
& Year produced & 2012 \\
& Number of emitters & 3
\end{tabular}

Emitter type

Spatial distribution of emitters

Beam delivery system

Center wavelength

Number of emitters

Spectral bandwidth

Operating mode

Peak radiant power

Average radiant power

Maximum frequency (frequency range)

- Pulse on duration

- Duty cycle

Aperture diameter

Irradiance at aperture

Beam divergence at $60 \%$

Beam profile

\section{Beam spot size at target area}

Irradiance at target

Radiant exposure (fluence)

Number of points irradiated

Exposure duration

Application technique

Timing

Number and frequency of treatment sessions

IR laser diodes

Three emitters spaced $2 \mathrm{~cm}$ apart in a triangle pattern

Scanning head (five pre-settled directions)

Laser diode 1

$808 \mathrm{~nm}$

1

$\pm 5 \mathrm{~nm}$

Continuous pulsed wave mode

$1.1 \mathrm{~W}$

$3.3 \mathrm{~W}$
Laser diode 2

$905 \mathrm{~nm}$

2

$\pm 5 \mathrm{~nm}$

$25 \mathrm{~W}$

$90 \mathrm{kHz}$

(1-2000 Hz)

- 100-ns single pulse width

$-50 \%$

$5 \mathrm{~cm}$

$0.168 \mathrm{~W} / \mathrm{cm}^{2}$

$42.8 \mathrm{mrad} \quad 59.2 \mathrm{mrad}$

Two laser beams work simultaneously and synchronously with coincident propagation axes

$19.625 \mathrm{~cm}^{2}$

$0.168 \mathrm{~W} / \mathrm{cm}^{2}$

$4 \mathrm{~J} / \mathrm{cm}^{2}$

-Breast:

Whole breast, inframammary fold and/or axilla, depending on the location of radiodermatitis

- Whole breast: $\pm 420-720 \mathrm{~s}$

- Inframammary fold: $\pm 103 \mathrm{~s}$

- Axilla: $\pm 68 \mathrm{~s}$

$5 \mathrm{~cm}$ above the skin

After the RT session

14 sessions in total, delivered biweekly from the first until the last day of RT over a period of 7 weeks

$I R$, infrared; $M L S$, Multiwave Locked System; PBMT, photobiomodulation therapy; $R D$, radiodermatitis; $R T$, radiotherapy 
Support Care Cancer

\section{Measurement collection schedule}

All the previously described measurements were collected on three time points: at the first day of RT, at a RT dose of $40 \mathrm{~Gy}$, and at the last day of RT (66 Gy).

\section{Statistical analysis}

Differences in patient- and therapy-related characteristics between both groups were analyzed by means of chi-square tests $\left(\chi^{2}\right)$, Fisher's exact tests, Student's $t$ tests, or Mann-Whitney $U$ tests, as appropriate. RTOG scores were analyzed by means of $\chi^{2}$ or Fisher's exact tests, as appropriate. The objective skin measurements at each time point were analyzed by MannWhitney $U$ tests. Longitudinal analysis of the biophysical skin measurements was performed by mixed analyses of variance (ANOVAs) with time (between the RT dose of 40 Gy and $66 \mathrm{~Gy}$ ) as within-subject factor and group (control vs. PBMT group) as between-subject factor. To determine the risk on moist desquamation, univariate logistic regressions with, as predictor variables, treatment group and breast size (based on the PTV) were performed. The level of statistical significance for all analyses was set assuming a significance level of $5 \%$ ( $p<0.05$, two-tailed). SPSS 24.0 (IBM, Chicago, IL) was used for all analyses.

\section{Results}

\section{Patient characteristics}

A total of 139 patients were randomized into the placebo or PBMT group between April 2015 and June 2017. During the course of RT, 2 patients of the control group withdrew their consent. Further 17 patients were excluded due to a RT regimen change or a RT interruption ( 5 and 8 in the control and PBMT, resp.). For the final analysis data of 120 patients, 60 patients in each group were used (Fig. 1). Both groups were

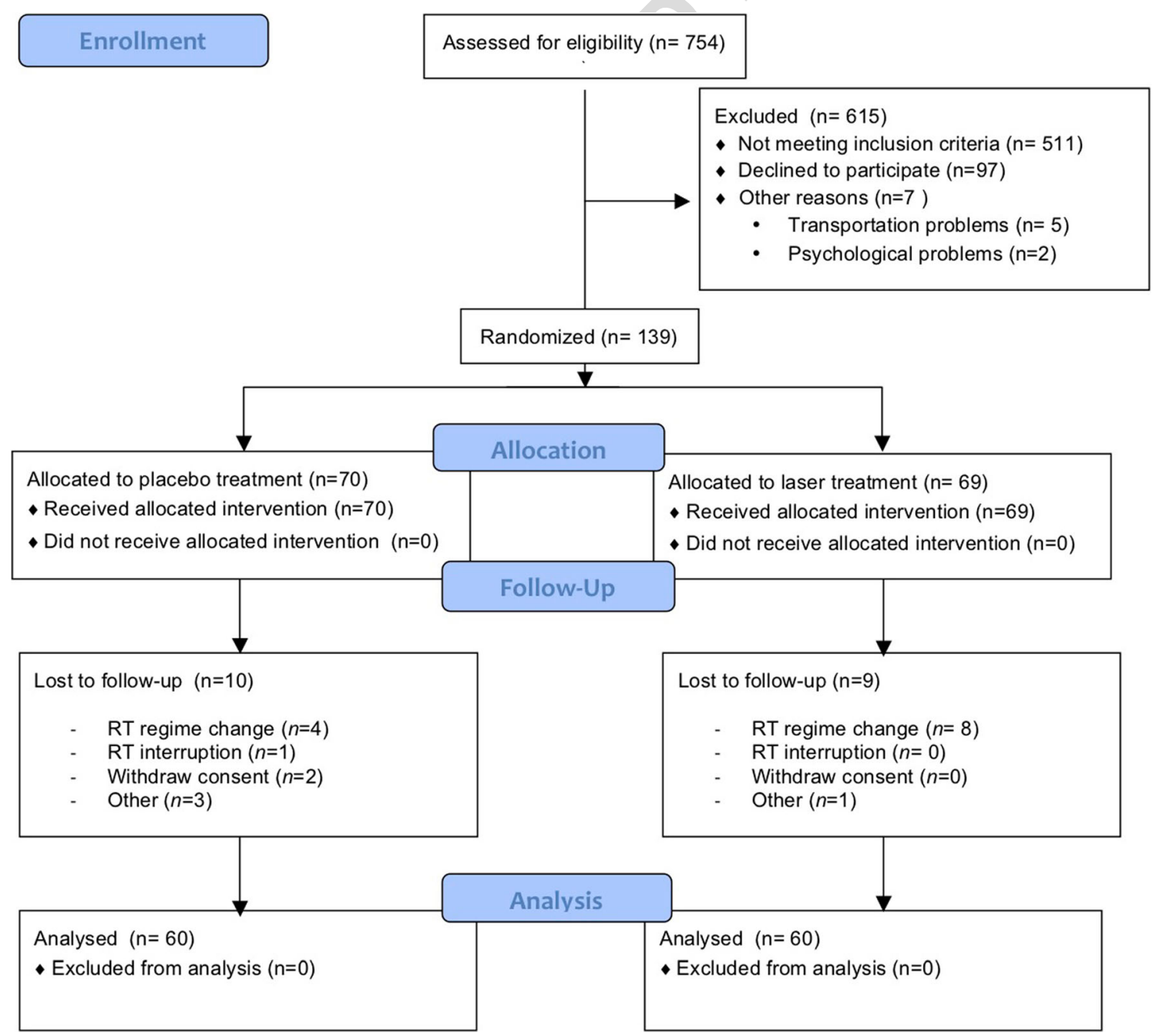

Fig. 1 CONSORT flow chart [14] 
t2.11 RT energy level, $n(\%)$

t2.12 $6 \mathrm{MV}$

$\mathrm{t} 2.136 \mathrm{MV}+15 \mathrm{MV}$

t2.14 Boost type, $n(\%)$

t2.15 Photons

t2.16 Electrons

t2.17 DIBH tics (Table 2).

\section{Erythema}

matched for all the patient- and treatment-related characteris-

\section{Clinical evaluation of ARD}

Patients' RT-induced skin reactions were evaluated by the criteria of the RTOG, as shown in Table 3. Our results demonstrated that the incidence of moist desquamation (ARD grade 2 or higher) was significantly lower in the PBMT group in comparison with the control group at the end of RT ( $p=$ $0.004)$. This was confirmed by the univariate logistic regression analysis demonstrating that patients only receiving the standard skin care were six times more likely to develop moist desquamation in comparison with patients that also were treatwith PBMT ( $p=0.003,95 \%$ CI [OR] 1.881-19.82). $800 \mathrm{cc}$ ) had a four times higher risk to develop moist desquamation than patients with small breast volumes $(p=0.017$, 95\% CI [OR] 1.290-12.936).

\section{Objective evaluation of ARD}

The mixed $2 \times 2$ ANOVAs revealed a significant main time effect and group by time interaction $(p s<0.05)$ for the erythema index. However, the main group effect was
Table 3 RTOG grading at a RT dose of 40 and 66 Gy (end RT)

RTOG grading Control group $(n=60) \quad$ PBMT group $(n=60) \quad p^{\mathrm{a}}$ $N(\%)$ $N(\%)$

\begin{tabular}{lccc}
\hline 40 Gray & & & 0.562 \\
Grade 1 & $1(1.7)$ & $3(5)$ & \\
Grade 2 & $55(91.7)$ & $54(90)$ & \\
Grade 3 & $4(6.7)$ & $3(5)$ & \\
66 Gray (end RT) & & & 0.004 \\
Grade 1 & $42(70)$ & $56(93.3)$ & \\
Grade 2 & $16(26.7)$ & $4(6.7)$ & \\
Grade 3 & $2(3.3)$ & $0(0)$ & \\
\hline
\end{tabular}

$P B M T$, photobiomodulation therapy; RTOG, Radiation Therapy Oncology Group (grade 0: no change; grade 1: follicular, dull, or faint erythema, dry desquamation; grade 2 : tender or bright erythema, patchy moist desquamation; grade 3: confluent moist desquamation other than skin folds)

${ }^{\text {a }}$ Chi-square tests (two-tailed)

not significant. As depicted in Fig. 2a, the degree of erythema in both groups increased during the course of RT. At the RT dose of $40 \mathrm{~Gy}$, the percentage change in erythema from baseline did not significantly differ between the control group and the PBMT group. However, at the end of RT, the percentage change from baseline in erythema was significantly higher in the control group in comparison with the PBMT group $(p=0.016)$. t3.1

$\mathrm{t} 3.2$

$\mathrm{t} 3.4$

$\mathrm{t} 3.5$

$\mathrm{t} 3.6$

$\mathrm{t} 3.7$

$\mathrm{t} 3.8$

$\mathrm{t} 3.9$

$\mathrm{t} 3.10$

$\mathrm{t} 3.11$

$D I B H$, deep inspiration breath-hold; $P B M T$, photobiomodulation therapy; $R T$, radiotherapy; $S D$, standard deviation

${ }^{a}$ Student's $t$ test, Wilcoxon-Mann-Whitney $U$ test, chi-square tests, or Fisher's exact tests, as appropriate (two-tailed)

${ }^{\mathrm{b}}$ Radiotherapy target volume that consists of the macroscopic primary tumor, the surrounding microscopic tumor spread and a margin to account for patient and/or organ movement, shape changes of the tumor, and daily setup variations. PTV was measured via treatment planning system by contouring manually each slice of breast tissue on planning CT 

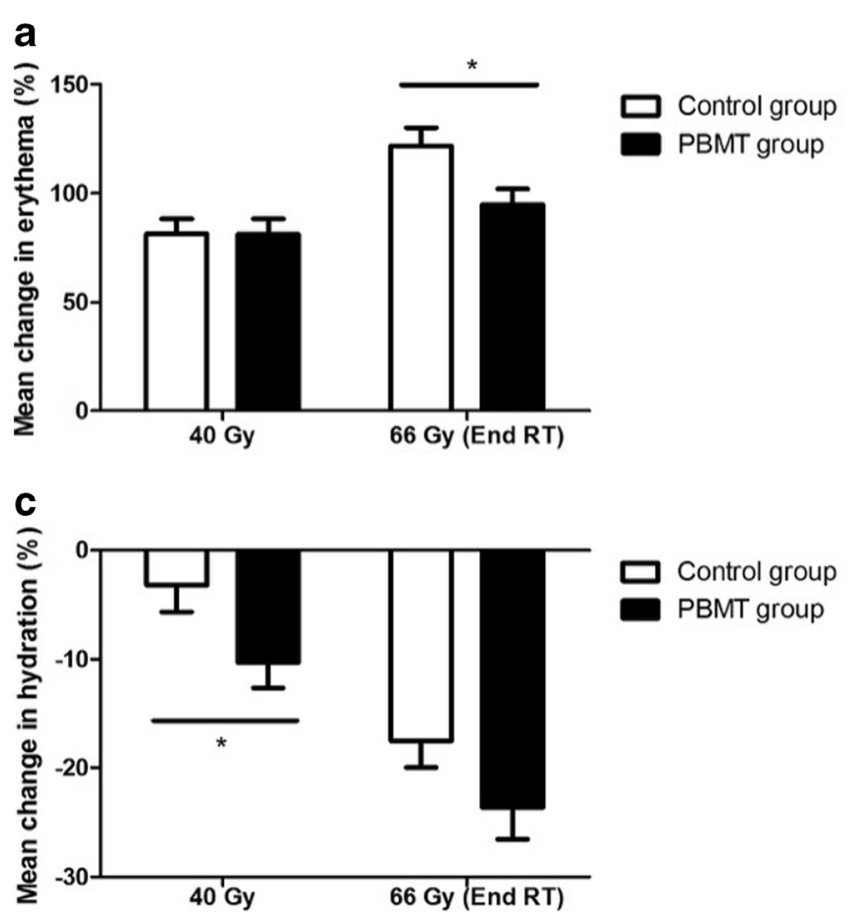

Fig. 2 Evaluation of the skin pigmentation (erythema (a) and melanin (b)) and barrier function (hydration (c) and TEWL (d)) by biophysical measurements. Data are shown as mean percentage change from baseline $( \pm$ SEM $)$ *Significant difference between the two groups at the indicated

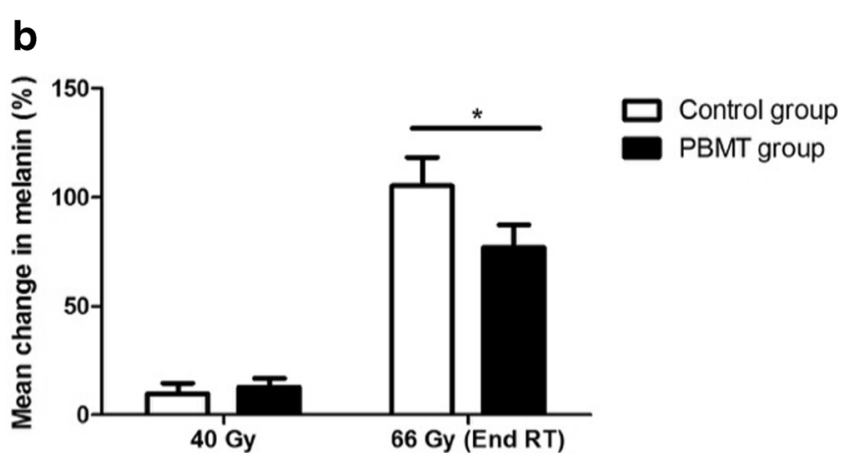

d

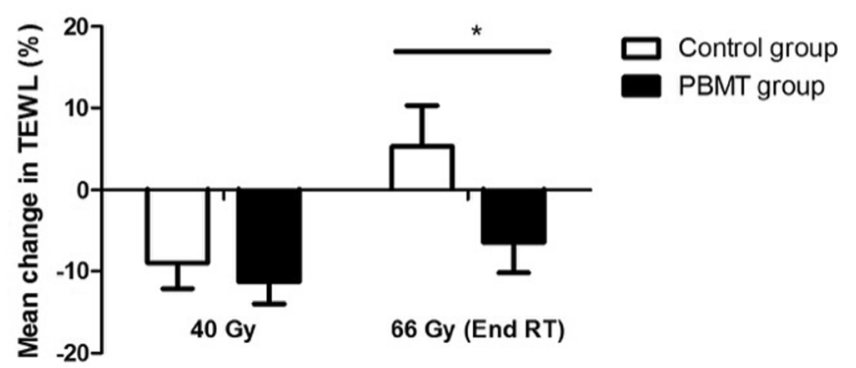

time point ( $p<0.05$; Mann-Whitney $U$ test, two-tailed). TEWL, transepidermal water loss; $P B M T$, photobiomodulation therapy; $R T$, radiotherapy

\section{Transepidermal water loss}

Regarding the TEWL, there was a significant main time and group effect ( $p s<0.05$ ), but no significant group by time interaction. The TEWL decreased in comparison with the baseline value in both the control and PBMT groups at the RT dose of 40 Gy, to a comparable level (Fig. 2d). Towards the end of RT, the TEWL level increased in both groups, although the final TEWL index was significantly lower in the PBMT group in comparison with the control group $(p=0.05)$.

\section{Discussion}

Results of this trial show that PBMT is an effective tool to prevent the development of moist desquamation. This was confirmed by objectively evaluating the skin's biophysical condition. Our results demonstrated that PBMT was able to reduce the increase in the skin's pigmentation level and improve the skin barrier function. Additionally, the main risk factor for the development of severe ARD is the breast volume, which implies that patients with large breasts (>800 cc) have an increased risk on moist desquamation.

The erythema index progressively increased during RT in both treatment arms. These findings are in line with previous studies [22-25]. This increase in erythema is caused by the 
RT-induced inflammatory reaction leading to vasodilation and leaking of the blood vessels [6, 26, 27]. However, the increase was significantly lower in the PBMT than in the control group at the end of RT. This proves that PBMT is able to reduce the degree of erythema. These results are consistent with earlier in vivo studies and clinical trials on various erythematous skin disorders (e.g., acne vulgaris, UV damage, laser resurfacing wounds, burn wounds) [28-31]. The anti-inflammatory effect of PBMT, correlated with a decrease in inflammatory cytokine production, might explain this observation [28, 32].

Further, our results also showed a significant increase in skin pigmentation in both groups during the course of RT. This is explained by post-inflammatory hyperpigmentation (PIH) after the RT-induced skin reaction [6, 27]. PIH is caused by the stimulation of melanocytes due to an inflammatory skin reaction leading to an increased melanin production and transport to the surrounding keratinocytes. Remarkably, our results demonstrated that at the end of RT, the increase in melanin content of the skin was significantly lower in the PBMT than in the control group. As such, PBMT was able to stabilize the hyperpigmentation reaction of the patients' skin during RT. Several in vitro studies showed that PBMT can inhibit the melanin synthesis in human melanocyte cultures [33]. Also, clinical trials demonstrated that PBMT is able to reduce hyperpigmentation in numerous skin conditions (e.g., acne vulgaris, photoaging, melasma) [34, 35].

In healthy skin, a low TEWL and a high hydration value correlate with a good barrier function [36]. Ionizing radiation deregulates the cellular function and causes apoptosis of the epidermal cells, resulting into an affected skin barrier function, correlated with a high TEWL and a low skin moisture level $[6,27,37,38]$. The findings in our control group are in line with these studies. However, in the PBMT group, both the TEWL and hydration index were significantly decreased at the end of RT. The epidermal thickening effect might explain these conflicting results. This effect is characterized by epidermal hyperproliferation leading to a thickened stratum corneum (outermost layer of the epidermis) caused by repetitive exposure to external stimuli. The thickening of the stratum corneum improves the skin barrier function and thereby it is correlated with a decrease in TEWL $[38,39]$. Several studies, both in vitro and in vivo, have demonstrated that PBMT can stimulate the proliferation of several types of cells, including keratinocytes. PBMT seems to be able to stimulate the epidermal thickening effect in the skin caused by RT and thereby it can improve the skin barrier function [40-43].

The results of the logistic regression analysis demonstrated that patients who were treated with standard skin care had a six time higher risk to develop moist desquamation in comparison with the patients treated with PBMT. This implies that the preventive application of
PBMT can seriously lower the severity of the RTinduced skin reactions, as previously published by our study group [14]. Further, our results showed that patients with large breasts developed more severe skin reactions. These findings are consistent with those of earlier published studies [44, 45].

The main limitation of the study was the enrolled patient population, which was confined to breast cancer patients postlumpectomy, who underwent a standard fractionated RT regimen. In the future, more clinical trials in a broader patient population with different cancer types and RT regimens need to be conducted, which will increase the generalizability of the study results.

\section{Conclusion}

This is the first RCT demonstrating by an objective approach that the preventive application of PBMT is effective in reducing the incidence of moist desquamation in breast cancer patients. The biophysical skin measurements showed that PBMT is able to stabilize the degree of pigmentation (both erythema and melanin) and improve the skin barrier function during the course of RT. Interestingly; patients with a large breast volume have an increased risk on moist desquamation. In conclusion, we can state that PBMT is an effective tool to prevent the development of severe ARD in breast cancer patients. Further, screening patients on breast volume before the start of RT can allow the radiotherapist to optimize the skin management during the course of RT.

Acknowledgments The corresponding author, Mrs. Jolien Robijns, received the Young Investigator Award of the MASCC for her scientific abstract.

Funding information This research is part of the Limburg Clinical Research Program (LCRP) UHasselt-ZOL-Jessa, financially supported by the foundation Limburg Sterk Merk, province of Limburg, Flemish government, Hasselt University, Ziekenhuis Oost-Limburg, and Jessa Hospital. Additionally, this research is supported by Kom op Tegen Kanker, Limburgs Kankerfonds, and ASA Srl.

\section{Compliance with ethical standards}

Conflict of interest The authors declare that they have no competing interests.

Ethical approval The ethics committees of the Jessa Hospital and the University of Hasselt approved the study (B243201524443). All procedures performed in the study were in accordance with the ethical standards of the institutional and national research committee and with the 1964 Helsinki declaration and its later amendments or comparable ethical standards.

Informed consent Informed consent was obtained from all individual participants included in the study. 


\section{References} New York 01801.x 22804
1. Wells M, MacBride S (2003) Radiation skin reactions. Elsevier,

2. Seite S, Bensadoun RJ, Mazer JM (2017) Prevention and treatment of acute and chronic radiodermatitis. Breast Cancer (Dove Med Press) 9:551-557. https://doi.org/10.2147/BCTT.S149752

3. Robijns J, Laubach H-J (2018) Acute and chronic radiodermatitis: clinical signs, pathophysiology, risk factors and management options. Journal of the Egyptian Women's Dermatologic Society 15(1):2-9. https://doi.org/10.1097/01.EWX.0000529960.52517.4c

4. Proksch E, Brandner JM, Jensen JM (2008) The skin: an indispensable barrier. Exp Dermatol 17(12):1063-1072

5. Cox JD, Stetz J, Pajak TF (1995) Toxicity criteria of the Radiation Therapy Oncology Group (RTOG) and the European Organization for Research and Treatment of Cancer (EORTC). Int J Radiat Oncol Biol Phys 31(5):1341-1346. https://doi.org/10.1016/03603016(95)00060-C

6. Hu SC, Hou MF, Luo KH, Chuang HY, Wei SY, Chen GS, Chiang W, Huang CJ (2014) Changes in biophysical properties of the skin following radiotherapy for breast cancer. J Dermatol 41(12):10871094. https://doi.org/10.1111/1346-8138.12669

7. Wong RK, Bensadoun RJ, Boers-Doets CB, Bryce J, Chan A, Epstein JB, Eaby-Sandy B, Lacouture ME (2013) Clinical practice guidelines for the prevention and treatment of acute and late radiation reactions from the MASCC Skin Toxicity Study Group. Support Care Cancer 21(10):2933-2948. https://doi.org/10.1007/ s00520-013-1896-2

8. Hamblin M, Ferraresi C, Huang YY, de Freitas LF, Carroll J (2018) Low-Level Light Therapy: Photobiomodulation. Tutorial Texts in Optical Engineering, vol TT115. SPIE Press, Bellingham 390

9. Schindl M, Kerschan K, Schindl A, Schon H, Heinzl H, Schindl L (1999) Induction of complete wound healing in recalcitrant ulcers by low-intensity laser irradiation depends on ulcer cause and size. Photodermatol Photoimmunol Photomed 15(1):18-21

10. DeLand MM, Weiss RA, McDaniel DH, Geronemus RG (2007) Treatment of radiation-induced dermatitis with light-emitting diode (LED) photomodulation. Lasers Surg Med 39(2):164-168. https:// doi.org/10.1002/1sm.20455

11. Fife D, Rayhan DJ, Behnam S, Ortiz A, Elkeeb L, Aquino L, Eduardo Roa D, Ramsinghani N, Kuo J, Newcomb R, Zachary CB, Kelly KM (2010) A randomized, controlled, double-blind study of light emitting diode photomodulation for the prevention of radiation dermatitis in patients with breast cancer. Dermatol Surg 36(12):1921-1927. https://doi.org/10.1111/j.1524-4725.2010.

12. Strouthos I, Chatzikonstantinou G, Tselis N, Bon D, Karagiannis E, Zoga E, Ferentinos K, Maximenko J, Nikolettou-Fischer V, Zamboglou N (2017) Photobiomodulation therapy for the management of radiation-induced dermatitis : a single-institution experience of adjuvant radiotherapy in breast cancer patients after breast conserving surgery. Strahlenther Onkol 193(6):491-498. https:// doi.org/10.1007/s00066-017-1117-x

13. Censabella S, Claes S, Robijns J, Bulens P, Mebis J (2016) Photobiomodulation for the management of radiation dermatitis: the DERMIS trial, a pilot study of MLS® laser therapy in breast cancer patients. Support Care Cancer 24:1-9. https://doi.org/10. 1007/s00520-016-3232-0

14. Robijns J, Censabella S, Claes S, Pannekoeke L, Bussé L, Colson D, Kaminski I, Bulens P, Maes A, Noé L, Brosens M, Timmermans A, Lambrichts I, Somers V, Mebis J (2018) Prevention of acute radiodermatitis by photobiomodulation: a randomized, placebocontrolled trial in breast cancer patients (TRANSDERMIS trial). Lasers Surg Med 50(7):763-771. https://doi.org/10.1002/1sm.
15. Burnet NG, Thomas SJ, Burton KE, Jefferies SJ (2004) Defining the tumour and target volumes for radiotherapy. Cancer Imaging 4(2):153-161. https://doi.org/10.1102/1470-7330.2004.0054

16. Nair RG, Bensadoun RJ (2016) Mitigation of cancer therapy sideeffects with light. Morgan \& Claypool Publishers, San Rafael

17. Zecha JA, Raber-Durlacher JE, Nair RG, Epstein JB, Elad S, Hamblin MR, Barasch A, Migliorati CA, Milstein DM, Genot MT, Lansaat L, van der Brink R, Arnabat-Dominguez J, van der Molen L, Jacobi I, van Diessen J, de Lange J, Smeele LE, Schubert MM, Bensadoun RJ (2016) Low-level laser therapy/ photobiomodulation in the management of side effects of chemoradiation therapy in head and neck cancer: part 2: proposed applications and treatment protocols. Support Care Cancer 24(6):27932805. https://doi.org/10.1007/s00520-016-3153-y

18. Pinnagoda J, Tupker RA, Agner T, Serup J (1990) Guidelines for transepidermal water loss (TEWL) measurement. A report from the Standardization Group of the European Society of Contact Dermatitis. Contact Dermatitis 22(3):164-178

19. Rogiers V, E. Group (2001) EEMCO guidance for the assessment of transepidermal water loss in cosmetic sciences. Skin Pharmacol Appl Ski Physiol 14(2):117-128 56341

20. Heinrich U, Koop U, Leneveu-Duchemin MC, Osterrieder K, Bielfeldt S, Chkarnat C, Degwert J, Hantschel D, Jaspers S, Nissen HP, Rohr M, Schneider G, Tronnier H (2003) Multicentre comparison of skin hydration in terms of physical-, physiologicaland product-dependent parameters by the capacitive method (Corneometer CM 825). Int J Cosmet Sci 25(1-2):45-53. https:// doi.org/10.1046/j.1467-2494.2003.00172.x

21. Clarys P, Alewaeters K, Lambrecht R, Barel AO (2000) Skin color measurements: comparison between three instruments: the Chromameter(R), the DermaSpectrometer(R) and the Mexameter(R). Skin Res Technol 6(4):230-238

22. Yamazaki H, Yoshida K, Kobayashi K, Tsubokura T, Kodani N, Aibe N, Ikeno H, Nishimura T (2012) Assessment of radiation dermatitis using objective analysis for patients with breast cancer treated with breast-conserving therapy: influence of body weight. Jpn J Radiol 30(6):486-491. https://doi.org/10.1007/s11604-0120073-8

23. Primavera G, Carrera M, Berardesca E, Pinnaro P, Messina M, Arcangeli G (2006) A double-blind, vehicle-controlled clinical study to evaluate the efficacy of MAS065D (XClair), a hyaluronic acid-based formulation, in the management of radiation-induced dermatitis. Cutan Ocul Toxicol 25(3):165-171. https://doi.org/10. 1080/15569520600860009

24. Yoshida EJ, Chen H, Torres MA, Curran WJ, Liu T (2011) Spectrophotometer and ultrasound evaluation of late toxicity following breast-cancer radiotherapy. Med Phys 38(10):5747-5755. https://doi.org/10.1118/1.3633942

25. Iacovelli NA, Naimo S, Bonfantini F, Cavallo A, Bossi P, Fallai C, Pignoli E, Alfieri S, Bergamini C, Favales F, Orlandi E (2017) Preemptive treatment with $\operatorname{Xonrid(R),~a~medical~device~to~reduce~}$ radiation induced dermatitis in head and neck cancer patients receiving curative treatment: a pilot study. Support Care Cancer 25(6):1787-1795. https://doi.org/10.1007/s00520-017-3569-z

26. Nystrom J, Geladi P, Lindholm-Sethson B, Rattfelt J, Svensk AC, Franzen L (2004) Objective measurements of radiotherapy-induced erythema. Skin Res Technol 10(4):242-250

27. Yamazaki H, Yoshida K, Kotsuma T, Kuriyama K, Masuda N, Nishimura T, Kobayashi K, Tsubokura T, Nishimura T (2009) Longitudinal practical measurement of skin color and moisture during and after breast-conserving therapy: influence of neoadjuvant systemic therapy. Jpn J Radiol 27(8):309-315. https://doi.org/10. 1007/s11604-009-0345-0

28. Hamblin MR (2017) Mechanisms and applications of the antiinflammatory effects of photobiomodulation. AIMS Biophys 4(3): 337-361. https://doi.org/10.3934/biophy.2017.3.337 
29. Gupta A, Keshri GK, Yadav A, Gola S, Chauhan S, Salhan AK, Bala Singh S (2015) Superpulsed (Ga-As, $904 \mathrm{~nm}$ ) low-level laser therapy (LLLT) attenuates inflammatory response and enhances healing of burn wounds. J Biophotonics 8(6):489-501. https://doi. org/10.1002/jbio.201400058

30. Khoury JG, Goldman MP (2008) Use of light-emitting diode photomodulation to reduce erythema and discomfort after intense pulsed light treatment of photodamage. J Cosmet Dermatol 7(1): 30-34. https://doi.org/10.1111/j.1473-2165.2008.00358.x

31. Barolet D, Boucher A (2008) LED photoprevention: reduced MED response following multiple LED exposures. Lasers Surg Med 40(2):106-112. https://doi.org/10.1002/1sm.20615

32. Chen CH, Wang CZ, Wang YH, Liao WT, Chen YJ, Kuo CH, Kuo HF, Hung CH (2014) Effects of low-level laser therapy on M1related cytokine expression in monocytes via histone modification. Mediat Inflamm 2014:625048. https://doi.org/10.1155/2014/ 625048

33. Kim HK, Min KO, Choi JH, Kim SH (2016) Effects of low-level laser therapy, electroacupuncture, and radiofrequency on the pigmentation and skin tone of adult women. J Phys Ther Sci 28(5): 1407-1411. https://doi.org/10.1589/jpts.28.1407

34. Lee SY, You CE, Park MY (2007) Blue and red light combination LED phototherapy for acne vulgaris in patients with skin phototype IV. Lasers Surg Med 39(2):180-188. https://doi.org/10.1002/lsm. 20412

35. Barolet D (2018) Photobiomodulation in dermatology: harnessing light from visible to near infrared. Medical Research Archives 6(1). https://oi.org/10.18103/mra.v6i1.1610

36. Baroni A, Buommino E, De Gregorio V, Ruocco E, Ruocco V, Wolf R (2012) Structure and function of the epidermis related to barrier properties. Clin Dermatol 30(3):257-262. https://doi.org/10.1016/j. clindermatol.2011.08.007

37. Schmuth M, Wimmer MA, Hofer S, Sztankay A, Weinlich G, Linder DM, Elias PM, Fritsch PO, Fritsch E (2002) Topical corticosteroid therapy for acute radiation dermatitis: a prospective, randomized, double-blind study. Br J Dermatol 146(6):983-991

38. Jensen JM, Gau T, Schultze J, Lemmnitz G, Folster-Holst R, May T, Abels C, Proksch E (2011) Treatment of acute radiodermatitis with an oil-in-water emulsion following radiation therapy for breast cancer: a controlled, randomized trial. Strahlenther Onkol 187(6):378384. https://doi.org/10.1007/s00066-011-2224-8

39. Park SY, Kim JH, Cho SI, Kim KI, Cho HJ, Park CW, Lee CH, Kim HO (2014) Induction of a hardening phenomenon and quantitative changes of ceramides in stratum corneum. Ann Dermatol 26(1):3542. https://doi.org/10.5021/ad.2014.26.1.35

40. Hawkins DH, Abrahamse H (2006) The role of laser fluence in cell viability, proliferation, and membrane integrity of wounded human skin fibroblasts following helium-neon laser irradiation. Lasers Surg Med 38(1):74-83. https://doi.org/10.1002/lsm.20271

41. Lanzafame RJ, Stadler I, Kurtz AF, Connelly R, Peter TA Sr, Brondon P, Olson D (2007) Reciprocity of exposure time and irradiance on energy density during photoradiation on wound healing in a murine pressure ulcer model. Lasers Surg Med 39(6):534-542. https://doi.org/10.1002/1sm.20519

42. Rizzi M, Migliario M, Tonello S, Rocchetti V, Reno F (2018) Photobiomodulation induces in vitro re-epithelialization via nitric oxide production. Lasers Med Sci 33:1003-1008. https://doi.org/ 10.1007/s10103-018-2443-7

43. Sperandio FF, Simoes A, Correa L, Aranha AC, Giudice FS, Hamblin MR, Sousa SC (2015) Low-level laser irradiation promotes the proliferation and maturation of keratinocytes during epithelial wound repair. J Biophotonics 8(10):795-803. https://doi. org/10.1002/jbio.201400064

44. Censabella S, Claes S, Orlandini M, Braekers R, Bulens P (2017) Efficacy of a hydroactive colloid gel versus historical controls for the prevention of radiotherapy-induced moist desquamation in breast cancer patients. Eur J Oncol Nurs 29:1-7. https://doi.org/ 10.1016/j.ejon.2017.04.003

45. De Langhe S, Mulliez T, Veldeman L, Remouchamps V, van Greveling A, Gilsoul M, De Schepper E, De Ruyck K, De Neve W, Thierens H (2014) Factors modifying the risk for developing acute skin toxicity after whole-breast intensity modulated radiotherapy. BMC Cancer 14:711. https://doi.org/10.1186/1471-2407-14711 


\section{AUTHOR QUERIES}

\section{AUTHOR PLEASE ANSWER ALL QUERIES.}

Q1. Please check if the affiliations are presented correctly.

Q2. Please check if the article note is presented correctly.

Q3. Please check if the section headings are assigned to appropriate levels.

Q4. Tables 1, 2, 3, and 4 were slightly modified. Please check if data are presented correctly.

Q5. Please supply/verify the standard abbreviation of the journal name in References Robijns and Laubach (2018) and Barolet (2018). 